\title{
First-Time Buyers' Subjective Knowledge and the Attribute Preferences of Chinese Car Buyers.
}

Lixian Qian, Didier Soopramanien (corresponding author), and Ahmad Daryanto

July 2016

Send correspondence to: Didier Soopramanien, Lancaster University Management School, Lancaster, LA1 4YX, UK, International Business School of Beijing Foreign Studies University, 19 North Xisanhuan Avenue, Beijing, 100089, China; Tel: +86-10-88815020, Email:

d.soopramanien@lancaster.ac.uk

Lixian Qian, International Business School Suzhou, Xi'an Jiaotong-Liverpool University, 111 Ren'ai Road, Suzhou Industrial Park, Jiangsu Province, 215123, China, Email:

$\underline{\text { lixian.qian@xjtlu.edu.cn }}$

Ahmad Daryanto, Lancaster University Management School, Lancaster, LA1 4YX, UK, Email:

a.daryanto@lancaster.ac.uk 


\begin{abstract}
.
This research focuses on the subjective knowledge of first time buyers (FTBs hereafter) and how it influences their preference attributes in a market, more specifically, the emerging Chinese car market. Previous research has considered the difference in the subjective knowledge of a product between owners and non-owners but does not account that some non-owners have stronger intentions to make a purchase. Yet, the impact of the purchase goal of FTBs on their subjective knowledge remains unexplained. This research demonstrates that the effect of the purchase goal on subjective knowledge is moderated by product ownership. Specifically, the findings show that the purchase goal only affects the level of subjective knowledge of FTB but not those of potential repurchasing buyers. Furthermore, when segmenting potential FTBs on the basis of their subjective knowledge, the segment of potential FTBs with higher subjective knowledge display similar attribute preferences to owners, while the preference differences are observed when segmenting potential buyers into owners and non-owners. From a managerial perspective, the findings of the research demonstrate the value of using subjective knowledge for consumer segmentation when targeting car buyers.
\end{abstract}

Key words: first time buyers, subjective knowledge, intention to buy, attribute preferences. 


\section{First-Time Buyers' Subjective Knowledge and the Attribute Preferences of Chinese Car}

\section{Buyers.}

\section{Introduction}

Consumer knowledge remains an important topic in marketing research and consumer behavior (Hong and Sternthal, 2010, Alba and Hutchinson, 2000). Consumer knowledge is defined as the information that consumers have when they face a purchase decision (Brucks, 1985). The literature differentiates between what consumers actually know, which is termed objective knowledge (OK, thereafter), and what consumers feel they know, referred to as subjective knowledge (SK, thereafter) (Carlson et al., 2009, Raju et al., 1995, Park et al., 1994). In that context Carlson et al (2009) provide a simple but yet insightful statement that differentiates between OK and SK: "OK reflects what we know and SK reflects that we think we know". The SK level of consumers in different product categories influences their attribute preferences and the brands that they will buy in that category (Moorman et al., 2004). Researchers posit that consumers' perception of their knowledge explains their information search process and how they interpret product information and, ultimately, the products they end up buying (Hadar et al., 2013, Bearden et al., 2001, Moorman et al., 2004).

Ownership of a product also influences how a consumer perceives his/her knowledge in any product category. Previous research shows that owners state that they know more about a product category than non-owners (Alba and Hutchinson, 2000, Park et al., 1994). This research however pays specific attention to non-owners and how their SK level changes if they intend to make a purchase and, more importantly, how this process affects their attribute preferences for the products that they intend to buy. In this study, we focus on potential Repurchasing 
Consumers (RPCs, thereafter) and potential First Time Buyers (FTBs, thereafter). This research argues that the typical segmentation of the market into owners and non-owners ignores that, within the segment of potential FTBs, some consumers have stronger purchase goals than others. Following Houston and Walker (1996), a purchase goal is referred to as a decision goal that is concrete (e.g., to purchase a car) and always active in consumer memory that leads to a sequence of a more specific behaviours (e.g., product search and an intention to purchase a specific product). Previous research shows that the purchase goal plays an important role in influencing the motivation of a consumer to acquire knowledge and subsequently which brand he/she will buy in the market (Huffman and Houston, 1993, Markman and Brendl, 2000, van Osselaer and Janiszewski, 2012). Huffman and Houston (1993) find that different types of consumers with different purchase goals will pay different levels of attention to the type of knowledge that they are acquiring or exposed to even if these different types of consumers are all searching for information about the same product. This implies that potential FTBs with a stronger purchase goal should be more motivated to learn and pay more attention to product information about a product category and consequently they should feel that their SK has increased compared to other FTBs with weaker intentions to buy a product. The main strategic and managerial implication of this research is as follows. Organizations risk misinterpreting the attribute preferences of new buyers in the market if they treat all FTBs as a homogenous group and fail to recognize two important relationships: (a) That the purchase goal of some FTBs changes their SK (b) within that segment of FTBs, the change in SK also leads to the different attribute preferences.

The empirical setting of this research is the Chinese car market. A key feature of this market is that, despite exponential growth in the past decade, it is still dominated by FTBs who 
have limited car ownership experience and the context can be labeled as an emerging car market (Qian and Soopramanien, 2014). A McKinsey Quarterly Report stated that over 60\% Chinese car buyers are buying their first cars (Atsmon et al., 2012). Thus, research on such types of emerging markets is very important. Generally, the research findings can be applied in other contexts where new products are being introduced and marketers need to consider how they wish to target potential new buyers of their product who may differ in terms of their SK levels and how each consumer segment reacts to marketing actions.

The remainder of the paper is organized as follows. In the next section, we discuss previous research related to our work and present our research hypotheses. Section 3 introduces the data that is used in this research and the empirical modeling that is used to explain the subjective knowledge of consumers. In Section 4, we first discuss how different factors explain subjective knowledge. In that same section, we also explore if the level of subjective knowledge of different types of buyers influences their attribute preferences. The last section discusses the implications of the research and also offers some directions for future research.

\section{Research Hypotheses}

\subsection{The Effects of Ownership Status and Purchase Goal on Subjective Knowledge}

Different types of consumers have different levels of knowledge about any product category but it is only when they face a purchase situation that they become aware of what they actually know (Park and Lessig, 1981, Carlson et al., 2009). It is that process of thinking about knowledge and the level of confidence about the knowledge that differentiates objective knowledge from subjective knowledge. Owners acquire and have a specific type of knowledge when they use the product compared to those who have never used that product. Park et al. (1994) find that product 
ownership experience has a more important role in positively influencing the SK level compared to other factors such as product-class information (e.g. product attributes, features, handling procedures and brands) and general self-confidence. In fact, Park et al (1994) found that both ownership and the ownership-related product experience have a bigger positive impact on SK than on OK. Carlson et al (2009) and Moorman et al (2004), amongst other researchers, argue that we need to better understand how different types of purchase situations trigger consumers to assess their knowledge. FTBs and RPCs who both intend to buy the same type of car face an identical purchase situation from the product perspective but their respective self-assessed product knowledge differs. Thus, RPCs are expected to perceive that they know more about a product category than those who have never used or owned that product (Alba and Hutchinson, 1987, Lambert-Pandraud et al., 2005). In the context of these findings in the literature, this study compares the SK of owners and non-owners and tests the following hypothesis:

H1: Product ownership has an impact on SK level such that potential Repurchasing Consumers (RPCs) s have a higher level of subjective knowledge than potential FTBs

This research also considers how a consumer's purchase goal influences his/her level of SK. Cognitive learning theory posits that consumers' knowledge acquisition is primarily involved with mental information processing and is motivated to reach a desirable state (i.e. approach goal) or move away from an undesirable state (i.e. avoidance goal) (Markman and Brendl, 2000). Consumer psychologists seek to understand how consumer's motivation drive their behaviors and how these motivations are linked with cognition and identify the gap in knowledge associated with these goals (Eccles and Wigfield, 2002). Researchers have found that consumers' 
goals can direct consumer's efforts to develop and organize their knowledge (Huffman and Houston, 1993, Eisenstein and Hutchinson, 2006) and further influence their decision making processes and choices (van Osselaer and Janiszewski, 2012, Markman and Brendl, 2000, Bagozzi and Dholakia, 1999).

Previous research has distinguished between consumers who are at different stages in their purchase goal; some may be browsing and others may intend to purchase cars (Hamilton and Chernev, 2010). Consumers who are browsing are less engaged in their information search activity whilst those who intend to purchase are more engaged and search for more specific information to support their immediate purchase needs (Putsis and Srinivasan, 1994, Moe, 2003). This research posits that a consumer's purchase goal is measured by viewing buying and browsing as opposite ends of a continuous scale. Given that different types of consumers have different levels in relation to information search, this research proposes the following hypothesis:

H2: The purchase goal is positively related to the level of subjective knowledge.

Since product ownership raises the level of SK (Alba and Hutchinson, 2000, Park et al., 1994), RPCs can rely heavily on their experience of the product to acquire knowledge when faced with a purchase decision. As for RPCs, although those who strongly intend to repurchase are able to conduct both internal and external information search to gain additional knowledge, they may feel that they have enough internal product knowledge and thus are less likely to search for information externally (Brucks, 1985). Conversely, compared to RPCs, FTBs who need to acquire more information are unable to acquire SK about a product from ownership experience up to a level similar to RPCs. Accordingly, since FTBs develop their perceived product 
knowledge in a different manner, this research proposes that the influence of FTBs' purchase goals will lead to a bigger change in their level of SK when we compare the same relationship for RPCs.

H3: Product ownership moderates the effect of the purchase goal on subjective knowledge

\subsection{The Effect Subjective Knowledge on Consumer Attribute Preferences}

The literature on consumer knowledge and SK generally suggests that the information acquisition process and existing perceived knowledge shape consumer preferences (Hadar et al., 2013, Moorman et al., 2004). Hadar et al. (2013) investigate the role of SK in circumstances where consumers consider different types of investment decisions. They find that consumers who think they know how to interpret the risk of different types of financial products were more likely to invest in risky portfolios. Moorman et al. (2004) investigate whether SK about dieting and fat content influence consumers' choices of products which are considered as healthy. They find that the more consumers feel confident about their knowledge the more it influences the category choice first and subsequently which alternatives enter their consideration set. Similarly, Oh and Abraham (2016) find that consumers with high subjective knowledge in a product category also perceive that they know the business practices of firms in that industry and paid attention to attributes relating to where the products come from

As stated above, this research posits that potential FTBs with stronger purchase goals are more motivated to search for information compared to other FTBs who have weaker purchase goals. Thus, it is important to determine whether FTBs' attributes preferences change when they search for information by comparing their preferences at different SK levels. 
Previous research also differentiates between extrinsic (e.g. price and country-of-origin) and intrinsic (e.g. function and performance) attributes (Zeithaml, 1988, Klein, 1998). Consumers acquire information about extrinsic attributes by searching from external sources but, importantly, when searching for such information, they feel that they can compare the different offers without purchasing or owning products. Typical extrinsic attributes include price, brand, warranty and store reputation (Raju et al., 1995, Wells et al., 2011). Conversely, to acquire intrinsic attribute information, more effort is required in searching or consumers may need to have some form of experience with the product (Rao and Monroe, 1988, Raju et al., 1995). Previous research has shown that with as knowledge increases, the importance of intrinsic attributes increases (Rao and Monroe, 1988), while extrinsic attributes might be relied less upon (Maheswaran, 1994) or only remains important for some extrinsic attributes such as price (Raju et al., 1995).

By distinguishing between intrinsic and extrinsic attributes, this research posits that, when FTBs search for product information, they will be able to acquire more information on extrinsic than on intrinsic attributes. The RPCs, on the other hand, through their product experience have more information on intrinsic attributes than FTBs. Thus, when the SK levels of FTBs increase, researchers should observe that FTBs' preferences for extrinsic attributes could become similar to those of RPCs whilst their preferences for intrinsic attributes should be less similar to those of RPCs. Thus, this research hypothesizes that:

H4(a): When the SK of FTBs increases, their extrinsic attribute preferences will become more similar to those of RPCs.

H4(b): When the SK of FTBs increases their intrinsic attribute preferences will not become more similar to those of RPCs. 
Figure 1 summarizes the hypotheses of the research in a conceptual model. The framework proposes depicts: (a) how product ownership and the purchase goal are positively related to a consumer's level of SK (H1 and H2) (b) the effect of the purchase goal on SK is moderated by the product ownership (H3), and (c) the increase in the SK level of FTBs will lead to similarity of preferences for extrinsic attributes between FTBs and RPCs but not in the case of intrinsic attributes (H4).

[Insert Figure 1 around here]

\section{Data and Methodology}

\subsection{Data}

The study uses data from a household survey conducted in China. A team of university students was employed as survey assistants to collect the data when they went back to their home cities during the Chinese New Year break. This study is thus able to collect data from a range of cities from four different major regions: East, Central, West and Northeast China. After deleting some responses with missing information, 524 respondents remain in the sample, with $20.2 \%$ from tier 1 cities including Beijing, Shanghai, Guangzhou and Shenzhen, 30.3\% from tier 2 cities that have regional influences and $49.5 \%$ from tier 3 and lower tier cities. Table 1 presents the demographic statistics of the sample. Given that car owners are over represented in the survey, this study re-weights the sample when estimating the empirical models based on family income and car ownership level of the national data from the 2010 China Statistical Yearbook (National Bureau of Statistics of China, 2010).

[Insert Table 1 around here] 
For the measurement of SK, the survey asked respondents to rate their perceived knowledge level with cars in general. Measuring SK in that manner using survey questions has been used previously by Brucks (1985), Hadar et al. (2013) and Park et al (1994). Respondents choose the following four options to describe the subjective knowledge about cars: no knowledge, basic knowledge, good knowledge or very good knowledge with cars. Very few respondents stated they were very familiar with cars, so this research combines respondents who chose the last two options to form a group of consumers with high SK about cars which effectively means there are three levels for that variable.

In the survey, we also collected data on respondents' purchase plan in the next 5 years, as a proxy of the purchase goal. It is an ordinal variable which is categorized into four levels of the purchase goal as follows: "plan to buy in the current year or next year", "plan to buy in 2-3 years", "plan to buy in 4-5 years" and "no specific purchase plan". In the empirical analysis, we use dummy variables to represent these respective levels of the purchase goal where the reference category is the most immediate goal (i.e. plan to buy in the current or next year). Also, in the sample, $72.3 \%$ of FTBs state they intend to buy a car in one of the next 5 years and $63.5 \%$ of RPCs state their intended year of buying a car but, for that group, they are effectively stating their intention to repurchase.

To compare the preference attributes of cars between different potential buyers, respondents were also asked to choose their preferred level for different attributes for the cars that they would like to buy. In this research, the focus is on comparing the preferences of RPCs and FTBs for extrinsic and intrinsic attributes respectively. In the case of extrinsic attributes, we compare the attribute preferences for price of cars and country of origin (COO thereafter) respectively. Similarly, in the case of intrinsic attributes, we compare fuel efficiency and the top 
speed of cars. To illustrate how the preference attributes were measured, as an example, in the case of the country of origin attribute, respondents were asked to choose which country of origin brand they preferred from Chinese, European, Other Asian, American brands as well as options not provided. In the same manner, for other attributes, they were given different levels to choose from. The choice distributions of the four attributes are provided in the next section when we empirically compare attribute preferences between RPCs and FTBs.

\subsection{Empirical Model Approach for Subjective Knowledge}

The SK level for each respondent is an ordinal variable with three levels and we therefore apply an ordered probit model to analyze the determinants of SK levels. In relation to the first three hypotheses of our study, the two focal predictor variables are the role of the purchase goal of different consumers and whether they already own a car. To ensure the robustness of our findings on the roles of purchase goal and ownership respectively, we also control for other factors that can influence the level of SK. Previous research shows that the SK level of consumers are influenced by demographic factors such as gender, age and income (Moorman et al., 2004). Related research has found that the number of licensed drivers or the proportion of licensed drivers in each family significantly increases household's vehicle adoption rates (Potoglou and Kanaroglou, 2008, Whelan, 2007) and therefore can influence consumers' SK in this particular product category. Table 2 presents the correlation matrix and descriptive statistics of all involved variables that are used for the empirical modeling of the SK level of consumers.

[Insert Table 2 around here] 
Suppose that consumer $i$ 's perception about his/her level of SK, represented as a latent variable $\mathrm{y}_{\mathrm{i}}$, is explained by an observable component $\mathrm{X}_{\mathrm{i}}$ and a residual $\varepsilon_{\mathrm{i}}$ :

$$
\mathrm{y}_{\mathrm{i}}=\mathrm{X}_{\mathrm{i}}+\varepsilon_{\mathrm{i}},
$$

where

$$
\begin{aligned}
X_{i}= & \beta_{0}+\beta_{1} \text { Household Income }_{i}+\beta_{2} \text { Age }_{i}+\beta_{3} \text { Gender }_{i}+\beta_{4} \text { Proportion of Drivers }_{i} \\
& +\beta_{5} \text { Car Ownership }_{i}+\beta_{6} \text { Purchase Goal }_{i} .
\end{aligned}
$$

The selected SK level, out of three levels defined by another variable $\mathrm{Y}_{\mathrm{j}}$, will be directly related to the latent variable $y_{i}$ and several related threshold values as follows (Franses and Paap, 2001, Train, 2003):

$$
Y_{i}=j \text {, if } \alpha_{j-1} \leq y_{i}<\alpha_{j}, \text { for } j=1, \cdots, 3 .
$$

To ensure the ordering, the threshold values must satisfy $\alpha_{0}<\alpha_{1}<\alpha_{2}<\alpha_{3}$. The boundary values, $\alpha_{0}$ and $\alpha_{3}$, are usually unknown and are set $\alpha_{0}=-\infty$ and $\alpha_{3}=+\infty$. For normalization purposes, this research follows Greene and Hensher (2010) to set the first threshold value $\alpha_{1}=0$, so that $Y_{i}=1$ if $y_{i}<0$. Therefore, only one ordered threshold $\left(\alpha_{2}\right)$ has to be estimated.

Given that the perceived level of SK in equation (1) and the ordered decision rule summarized in equation (3), the choice probability of each alternative in the ordered model is

$$
\operatorname{Prob}\left(Y_{i}=j\right)=\operatorname{Prob}\left(\alpha_{j-1}-X_{i} \leq \varepsilon_{i}<\alpha_{j}-X_{i}\right)
$$

If $F(\cdot)$ is the cumulative distribution function of $\varepsilon_{\mathrm{i}}, \mathrm{F}\left(\alpha_{0}-\mathrm{X}_{\mathrm{i}}\right)=0$ and $\mathrm{F}\left(\alpha_{3}-\mathrm{X}_{\mathrm{i}}\right)=1$. Thus, the individual's choice probability of each SK level is 


$$
\operatorname{Prob}\left(Y_{i}=j\right)=\left\{\begin{array}{cc}
F\left(-X_{i}\right) & j=1 \\
F\left(\alpha_{2}-X_{i}\right)-F\left(-X_{i}\right) & j=2 \\
1-F\left(\alpha_{2}-X_{i}\right) & j=3
\end{array}\right.
$$

The ordered probit model assumes that $\varepsilon_{\mathrm{i}}$ follows i.i.d. standard normal distribution (Franses and Paap, 2001, Train, 2003, Greene and Hensher, 2010).We estimate three ordered probit models. The first model described in equation 2 above is applied to the whole sample. We then segment our dataset and consider the SK levels of RPCs and FTBs separately and estimate an ordered probit model for each segment. Since ownership is used as the segmentation variable, we exclude ownership of cars as a predictor variable for the ordered probit models for RPCs and FTBs respectively. Effectively, the three ordered probit models will allow us to compare the effects of purchase goal on the level of SK for (i) all potential buyers, (i) RPCs and (iii) FTBs, whilst controlling for the effect of other predictor variables.

\section{Results}

\subsection{Subjective Knowledge Analysis Results}

The first three hypotheses proposed in this research investigate whether car ownership and purchase goal influence the level of SK. We start with a comparison of the SK levels between FTBs and RPCs and Figure 2 depicts the distribution of the level of SK between these two segments. As expected, RPCs are more likely to state that they have the higher SK compared to FTBs $\left(\chi^{2}=25.24\right.$, d.f. $\left.=2, p<0.00\right)$. To complement this analysis, we consider the results of the ordered probit models discussed above, which are presented in Table 3. Model 1 is the ordered probit for the whole sample and Models 2 and 3 are the ordered probit models for RPCs and FTBs respectively. 
[Insert Figure 2 and Table 3 around here]

The results of model 1 (all potential buyers) indicate that car ownership has a positive effect on the SK level when we control for the effect of other factors. This finding thus provides further evidence that supports results above that RPCs do indeed perceive that they have a higher level of SK than FTBs. These two sets of results therefore support H1 and this corroborates with previous research that finds that product-specific experience is an important factor in influencing consumers' SK development (Park et al., 1994, Alba and Hutchinson, 2000).

What is of most interest, however, is the role of the purchasing goal on the levels of SK for RPCs and FTBs respectively (models 2 and 3 in Table 3). For RPCs, in Model 2, we note that none of the purchase goal dummy variables is significant in influencing the level of SK. For FTBs in Model 3, however, the results indicate that those FTBs with the lowest level of purchase goal (i.e. those without a specific purchase plan) have significantly lower levels of SK compared to other FTBs who plan to purchase in current or next year, and no significant difference is observed amongst FTBs with other levels of specific purchase goals. It is important to reiterate here that we obtain these effects for both groups even when we account for other control variables. So these results partially support $\mathrm{H} 2$ in the sense that the purchase goal only affects the level of SK for FTBs only. RPCs, who are owners and going to repurchase, are not as motivated to increase their SK, even if some of them may have more specific purchase goals. This implies that RPCs rely more on their ownership experience when accessing their knowledge of cars before repurchasing. In comparison, once FTBs have a specific purchase goal, they are more motivated to acquire more product information to develop their SK because they cannot rely on 
product ownership knowledge before purchasing. Therefore, the comparative effect of the purchase goal on the SK level between RPCs and FTBs fully supports H3 where our findings indicate that ownership moderates the effect of purchase goal on the level of subjective knowledge.

\subsection{Subjective Knowledge and the Attribute Preferences of FTBs.}

Findings from previous research indicate that RPCs and FTBs differ in their attribute preferences (Qian and Soopramanien, 2011, Okada, 2006). But these findings do not account for the effect of the purchase goal on the SK level of FTBs. It is therefore important to evaluate if the effect of the purchase goal on the SK of FTBs still renders their attribute preferences to significantly differ from RPCs. The last hypothesis of this study (H4) proposes that FTBs with no product ownership experience may feel that they can obtain and easily interpret the information on extrinsic attributes but that the same process may be more difficult in the case of intrinsic attributes. This follows Klein (1998) who posited that buyers, who have not used a product before, lack information on experiential and intrinsic attributes. To test this hypothesis, this research investigates whether the change in the SK level for FTBs influences their attribute preference heterogeneity in comparison to RPCs and in relation to intrinsic and extrinsic attributes respectively. As mentioned previously, the comparison of attribute preferences involves two extrinsic attributes, purchase price and country-of-origin and two performancerelated intrinsic attributes of cars, fuel efficiency and top speed. For each attribute, this research first compares the preferences of FTBs and RPCs, and then segments FTBs based on their levels of SK and examines their preference heterogeneity (or homogeneity) against RPCs as a reference category. 
[Insert 4 and Table 5 around here]

The choice of attribute levels for the vehicle price significantly differs between RPCs or FTBs $\left(\chi^{2}=67.46, p<0.01\right)$ as can be seen in Table 4 . When examining the effect of the level of SK, the results suggest that FTBs with the higher levels of SK have less heterogeneous preferences for the purchase price when compared to RPCs $(p=0.06)$, as indicated by the decreasing $\chi^{2}$ values for FTBs with increasing levels of SK (see Table 4). For the COO attribute (see table 5), this research finds a similar pattern in that an increase in the level of SK of FTBs reduces the differences in preferences between RPCs and FTBs. When comparing the different levels of attributes choice for COO, FTBs with no and basic SK respectively has significantly different preferences compared to RPCs $(p<.01)$. However, FTBs with good SK have similar preferences to RPCs when it comes to COO $(p=0.22)$. For example, FTBs without good SK prefer the domestic (Chinese) brands followed by the European brands, but RPCs and FTBs with good SK have little preference to the Chinese brands. In summary, these results support H4(a). Previous studies on COO such as Schaefer (1997) and Lee and Lee (2009) find that new buyers favor brands in a product category typically associated with a country as they have less knowledge than owners. With respect to this relationship, this research posits that FTBs with higher levels of SK have searched for product information and thus become less reliant on COO.

[Insert Tables 6 and 7 around here] 
Tables 6 and 7 respectively show the effect of SK on the preferences of two intrinsic attributes. For the fuel efficiency attribute, RPCs prefer vehicles with high fuel consumption rate (>10 liter/100 km) compared to those with high fuel efficiency (<8 liter/100 km). Conversely, as a whole segment, FTBs have the significantly different preferences $\left(\chi^{2}=13.38, p<0.01\right)$. When FTBs are further segmented based on their levels of SK, their preference heterogeneity against RPCs diminishes as the level of SK increases for FTBs. For example, for FTBs with basic SK, their preference heterogeneity compared with RPCs is significant at the 5\% level. However, FTBs with good SK have similar preferences to RPCs $\left(\chi^{2}=3.72, p=0.16\right)$. For top speed attribute in table 7, the research identifies a similar relationship in which the preferences of FTBs become more similar to those of RPCs when FTBs' SK level rises. Therefore, the findings do not support $\mathrm{H} 4$ (b) in relation to the preferences for the two intrinsic attributes

Previous work posits that FTBs can easily acquire knowledge on extrinsic attributes and get a better grasp of what the different levels of such attributes mean compared to having the same level of confidence in being able to judge the intrinsic attributes. Extrinsic attributes are more easily observable, hence easily interpretable, whilst intrinsic attributes are often unobservable before purchase (Zeithaml, 1988). If this is the case and that knowledge acquisition influences preference attributes, it would be expected that, as FTBs acquire more product knowledge, their attribute preferences would become more similar to RPCs but only for extrinsic attributes. The most interesting insight of this study concerns the process by which the increase in the SK level for FTBs changes their preference attributes in such a way that their preferences become similar to attribute preference of RPCs. In our study, FTBs with higher purchasing goals feel that they are better able to interpret the intrinsic attributes whilst previous research posits that they would find it difficult to do so. We posit that this is due to consumers' increasing use 
of the Internet to search for product information (including online product reviews). For the car market, Ratchford et al. (2007) find that consumers are using the Internet to obtain information that they could instead obtain from car dealers. The growing trend of sharing product experiences using social media is making it easier for FTBs without prior product experience to acquire and interpret this sort of product information on intrinsic attributes (Klein, 1998, Bei et al., 2004).

\section{Conclusions, Limitations and Future Research.}

Consumer knowledge and its related affective construct of subjective knowledge remains an important domain of research due to their respective effects on consumer preferences. This research contributes to this body of work by demonstrating the importance of studying and analyzing the subjective knowledge of different types of consumers to better understand their preferences. Previous research has shown that owners of a product are more confident about their knowledge compared to those who do not own that product. Our research provides further evidence to support this hypothesis. However, in terms of our specific contribution to the literature on subjective knowledge, as far as the authors are aware, there has not been much work on first time buyers and more specifically about how the relationship between their subjective knowledge and their purchase goal influences their attribute preferences. Consequently, our study's findings allow us to posit that the typical approach of segmenting the consumer market into two broad segments of owners and non-owners fails to recognize that the latter group are not a homogenous group of consumers and that their purchase goal and their subjective knowledge level should be considered when studying preferences of buyers in a market. This is shown by comparing the insight on the attribute preferences of potential FTBs based on two contrasting 
assumptions: (i) all potential FTBs have the same level of subjective knowledge versus (ii) different potential FTBs have different levels of subjective knowledge. If the exercise of further segmenting the group of FTBs using their subjective knowledge is not conducted, one observes that their preferences are significantly different to RPCs. However, this research shows that the preferences of potential FTBs, whether it is for extrinsic or intrinsic attributes, become more similar to RPCs when the former's subjective knowledge increases. The subjective knowledge of some potential FTBs increases because they strongly intend to make a purchase and as such they need to acquire product knowledge compared to other first time buyers. The results also indicate that the levels of subjective knowledge of RPCs do not increase significantly even if they have a strong purchase goal. RPCs who strongly intend to buy do not have to put as much effort in searching externally and can rely more on the product ownership experience. Thus, their purchase goal does not have a significant effect on their subjective knowledge.

The literature posits that the level of consumer knowledge influences the attribute preferences of consumers and in particular the intrinsic and extrinsic attributes (Raju et al., 1995, Rao and Monroe, 1988). When potential FTBs learn and increase their subjective knowledge it is typically argued that they can only learn about extrinsic attributes and it is difficult for them to judge intrinsic attributes. In the latter case, to be able to compare intrinsic attributes, consumers need to experience a product. A car owner who regularly uses a car has a better understanding of fuel efficiency than a first time buyer. If this is the case, one would expect that the gap in preferences between repurchasing consumers and first time buyers to decrease only in the case of extrinsic attributes because information on such attributes is easier to obtain (Zeithaml, 1988). This research finds that the way in which consumers are now able to gather information for different types of attributes can lead to a situation where the difference between intrinsic and 
extrinsic attribute preferences is not as demarcating as initially proposed by the literature. The specific implication of this finding relates to how potential FTBs in a market are able learn about and compare intrinsic attributes when they have never used a product. This is particularly important given the role of the Internet as part of the consumer search process (Klein, 1998, Bei et al., 2004), especially as social platforms such as YouTube enable users to document and share their experience with non-users and potential buyers of a product.

The empirical context of this research is the Chinese car market which is the largest car market in terms of cars sales. However, the managerial relevance of the findings can be generalized at both strategic and tactical levels to more general market contexts with large numbers of FTBs (e.g. in other emerging economies) or when considering the initial market context for radically new innovations. At the strategic level, this research provides critical managerial implication to improve the market segmentation and targeting. Organizations typically segment the market into owners and non-owners and then differentiate their market offers (including pricing decisions and promotion efforts) for these two segments. Organizations adopting such a segmentation strategy may underestimate the degree of within-market heterogeneity in emerging economies (Burgess and Steenkamp, 2006), especially where first time buyers dominate the market. The owner versus non-owner segmentation ignores the fact that some non-owners are motivated to increase their knowledge and hence how they feel about how much they know. Although potential FTBs and RPCs increase their subjective knowledge through different processes, the preferences of these two groups of consumers become similar as the subjective knowledge of FTBs increases. The findings of this research show that segmentation and targeting strategies will be more effective when taking into consideration that the knowledge of consumers increases when they intend to buy instead of just using the 
ownership status of consumers in the market. Marketing strategies and decisions should be designed to target at least three segments: repurchasing consumers, potential first time buyers with low and high subjective knowledge respectively.

At a more tactical and operational level, this research offers additional suggestions in terms of how to engage with customers, especially new buyers, when they are searching for information. This research finds that, due to their stronger goal to purchase, some potential first time buyers are thinking and searching for information more proactively, which, in turn, significantly influences their attribute preferences. Thus, organizations must think about their strategies for engaging with potential customers by directing more attention to the information search process and in particular how consumers are searching for information and the type of information they are searching for.

The Internet now plays a significant role in the information search process and brand managers must pay more attention how they can use online platform tools (such as allowing users to document their experience through videos or blogging) to give information to new buyers that relate to experiencing the product. A study by J.D. Power Asia Pacific (2014) on how car buyers search for information recommends that brand managers should make better use of their official websites and online social media platforms to engage potential car buyers with compelling contents. Brand managers must start to audit the information (relating to both extrinsic and intrinsic attributes) may already be available on their brands or their competitors' brands.

This research contributes to the literature on the importance of subjective knowledge and in the process of conducting the research we have identified some limitations that also constitute avenues for further research. First, the present research finds that potential FTBs' preferences 
change when their subjective knowledge increases and it is important to examine further the process that leads to the change in the attribute preferences. Therefore, an important future research direction is to investigate how first time buyers learn about product attributes, which specific sources they use and which of those sources are more important in gathering product knowledge.

Second, the present research only measures the overall level of subjective knowledge of each consumer on the product. This research proposes that it is important to gather data on the subjective knowledge of consumers on different attributes of a product. This would then enable further investigation of the antecedents of consumer's knowledge on intrinsic and extrinsic attributes and how they affect the choice of different types of brands.

Thirdly, this research has considered the car market in China. The findings of this research on subjective knowledge can be generalized to other product categories where the market can be segmented in a similar way.

\section{Acknowledgements}

The authors thank Yuxin Chen, Min Ding, Robert Fildes, Zhan Pang, Vernon Richardson, and seminar participants at Nanjing University for their helpful comments on the earlier versions of the paper. Some of the research work for this paper is supported by the National Natural Science Foundation of China (Grant No. 71573213). 


\section{REFERENCES}

Alba, J. W. and Hutchinson, J. W. (1987), "Dimensions of consumer expertise", Journal of Consumer Research, Vol. 13 No. 4, pp. 411-454.

Alba, J. W. and Hutchinson, J. W. (2000), "Knowledge calibration: What consumers know and what they think they know", Journal of Consumer Research, Vol. 27 No. 2, pp. 123-156.

Atsmon, Y., Kuentz, J.-F. and Seong, J. (2012), "Building brands in emerging markets", McKinsey Quarterly, McKinsey \& Company, London, Taipei and Shanghai.

Bagozzi, R. P. and Dholakia, U. (1999), "Goal setting and goal striving in consumer behavior", Journal of Marketing, Vol. 63 No. 4, pp. 19-32.

Bearden, William o., Hardesty, David m. and Rose, Randall 1. (2001), "Consumer selfconfidence: Refinements in conceptualization and measurement", Journal of Consumer Research, Vol. 28 No. 1, pp. 121-134.

Bei, L.-T., Chen, E. Y. and Widdows, R. (2004), "Consumers' online information search behavior and the phenomenon of search vs. experience products", Journal of Family and Economic Issues, Vol. 25 No. 4, pp. 449-467.

Brucks, M. (1985), "The effects of product class knowledge on information search behavior", Journal of Consumer Research, Vol. 12 No. 1, pp. 1-16.

Burgess, S. M. and Steenkamp, J. B. E. M. (2006), "Marketing renaissance: How research in emerging markets advances marketing science and practice", International Journal of Research in Marketing, Vol. 23 No. 4, pp. 337-356.

Carlson, J. P., Vincent, L. H., Hardesty, D. M. and Bearden, W. O. (2009), "Objective and subjective knowledge relationships: A quantitative analysis of consumer research findings", Journal of Consumer Research, Vol. 35 No. 5, pp. 864-876. 
Clarkson, J. J., Janiszewski, C. and Cinelli, M. D. (2013), "The desire for consumption knowledge", Journal of Consumer Research, Vol. 39 No. 6, pp. 1313-1329.

Eccles, J. S. and Wigfield, A. (2002), "Motivational beliefs, values, and goals", Annual review of psychology, Vol. 53 No. 1, pp. 109-132.

Eisenstein, E. M. and Hutchinson, J. W. (2006), "Action-based learning: Goals and attention in the acquisition of market knowledge", Journal of Marketing Research, Vol. 43 No. 2, pp. 244-258.

Franses, P. H. and Paap, R. (2001), Quantitative models in marketing research, Cambridge University Press, Cambridge.

Greene, W. H. and Hensher, D. A. (2010), Modeling ordered choices : a primer, Cambridge University Press, Cambridge.

Hadar, L., Sood, S. and Fox, C. R. (2013), "Subjective knowledge in consumer financial decisions", Journal of Marketing Research, Vol. 50 No. 3, pp. 303-316.

Hamilton, R. and Chernev, A. (2010), "The impact of product line extensions and consumer goals on the formation of price image", Journal of Marketing Research, Vol. 47 No. 1, pp. 5162.

Hong, J. and Sternthal, B. (2010), "The effects of consumer prior knowledge and processing strategies on judgments", Journal of Marketing Research, Vol. 47 No. 2, pp. 301-311.

Houston, M. B. and Walker, B. A. (1996), "Self-relevance and purchase goals: mapping a consumer decision", Journal of the Academy of Marketing Science, Vol. 24 No. 3, pp. 232245.

Huffman, C. and Houston, M. J. (1993), "Goal-oriented experiences and the development of knowledge", Journal of Consumer Research, Vol. 20 No. 2, pp. 190-207. 
J.D. Power Asia Pacific (2014), "The Internet has the greatest impact among all media channels on shoppers' new-vehicle purchase decisions", available at: http://china.jdpower.com/pressreleases/2014-china-auto-media-study-ams-0 (accessed August 22 2014).

Klein, L. R. (1998), "Evaluating the potential of interactive media through a new lens: search versus experience goods", Journal of Business Research, Vol. 41 No. 3, pp. 195-203.

Lambert-Pandraud, R., Laurent, G. and Lapersonne, E. (2005), "Repeat purchasing of new automobiles by older consumers: empirical evidence and interpretations", Journal of Marketing, Vol. 69 No. 2, pp. 97-113.

Lee, J. K. and Lee, W.-N. (2009), "Country-of-origin effects on consumer product evaluation and purchase intention: the role of objective versus subjective knowledge", Journal of International Consumer Marketing, Vol. 21 No. 2, pp. 137-151.

Maheswaran, D. (1994), "Country of origin as a stereotype: Effects of consumer expertise and attribute strength on product evaluations", Journal of Consumer Research, Vol. 21 No. 2, pp. 354-365.

Markman, A. B. and Brendl, C. M. (2000), "The influence of goals on value and choice", Psychology of learning and motivation, Vol. 39 No., pp. 97-128.

Moe, W. W. (2003), "Buying, searching, or browsing: differentiating between online shoppers using in-store navigational clickstream", Journal of Consumer Psychology, Vol. 13 No. 1/2, pp. 29.

Moorman, C., Diehl, K., Brinberg, D. and Kidwell, B. (2004), "Subjective knowledge, search locations, and consumer choice", Journal of Consumer Research, Vol. 31 No. 3, pp. 673-680. National Bureau of Statistics of China (2010), China Statistical Yearbook 2010, China Statistics Press, Beijing. 
Okada, E. M. (2006), "Upgrades and new purchases", Journal of Marketing, Vol. 70 No. 4, pp. 92-102.

Park, C. W., Mothersbaugh, D. L. and Feick, L. (1994), "Consumer knowledge assessment", Journal of Consumer Research, Vol. 21 No. 1, pp. 71-82.

Potoglou, D. and Kanaroglou, P. S. (2008), "Modelling car ownership in urban areas: a case study of Hamilton, Canada", Journal of Transport Geography, Vol. 16 No. 1, pp. 42-54.

Putsis, W. P., Jr. and Srinivasan, N. (1994), "Buying or just browsing? The duration of purchase deliberation", Journal of Marketing Research, Vol. 31 No. 3, pp. 393-402.

Qian, L. and Soopramanien, D. (2011), "Heterogeneous consumer preferences for alternative fuel cars in China", Transportation Research Part D-Transport and Environment, Vol. 16 No. 8, pp. 607-613.

Qian, L. and Soopramanien, D. (2014), "Using diffusion models to forecast market size in emerging markets with applications to the Chinese car market", Journal of Business Research, Vol. 67 No. 6, pp. 1226-1232.

Raju, P. S., Lonial, S. C. and Mangold, W. G. (1995), "Differential effects of subjective knowledge, objective knowledge, and usage experience on decision making: An exploratory investigation", Journal of Consumer Psychology, Vol. 4 No. 2, pp. 153-180.

Rao, A. R. and Monroe, K. B. (1988), "The moderating effect of prior knowledge on cue utilization in product evaluations", Journal of Consumer Research, Vol. 15 No. 2, pp. 253264.

Schaefer, A. (1997), "Consumer knowledge and country of origin effects", European Journal of Marketing, Vol. 31 No. 1, pp. 56-72. 
Train, K. E. (2003), Discrete choice methods with simulation, Cambridge University Press, Cambridge, MA.

Van Osselaer, S. M. J. and Janiszewski, C. (2012), "A goal-based model of product evaluation and choice", Journal of Consumer Research, Vol. 39 No. 2, pp. 260-292.

Wells, J. D., Valacich, J. S. and Hess, T. J. (2011), "What signals are you sending? How website quality influences perceptions of product quality and purchase intentions", MIS quarterly, Vol. 35 No. 2, pp. 373-396.

Whelan, G. (2007), "Modelling car ownership in Great Britain", Transportation Research Part A: Policy and Practice, Vol. 41 No. 3, pp. 205-219.

Zeithaml, V. A. (1988), "Consumer perceptions of price, quality, and value: a means-end model and synthesis of evidence", Journal of Marketing, Vol. 52 No. 3, pp. 2-22. 
Figure 1: Research Framework

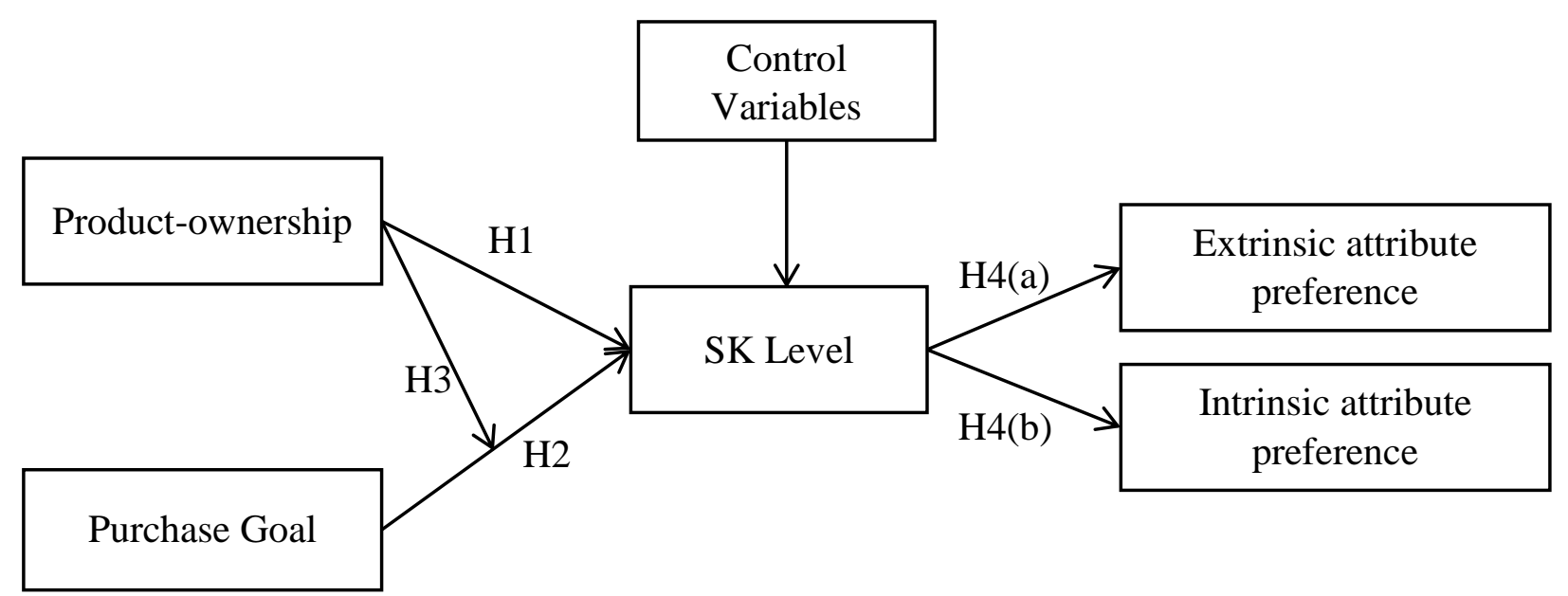


Figure 2: SK distribution of first time buyers and repurchasing consumers

\section{Number of \\ respondents}

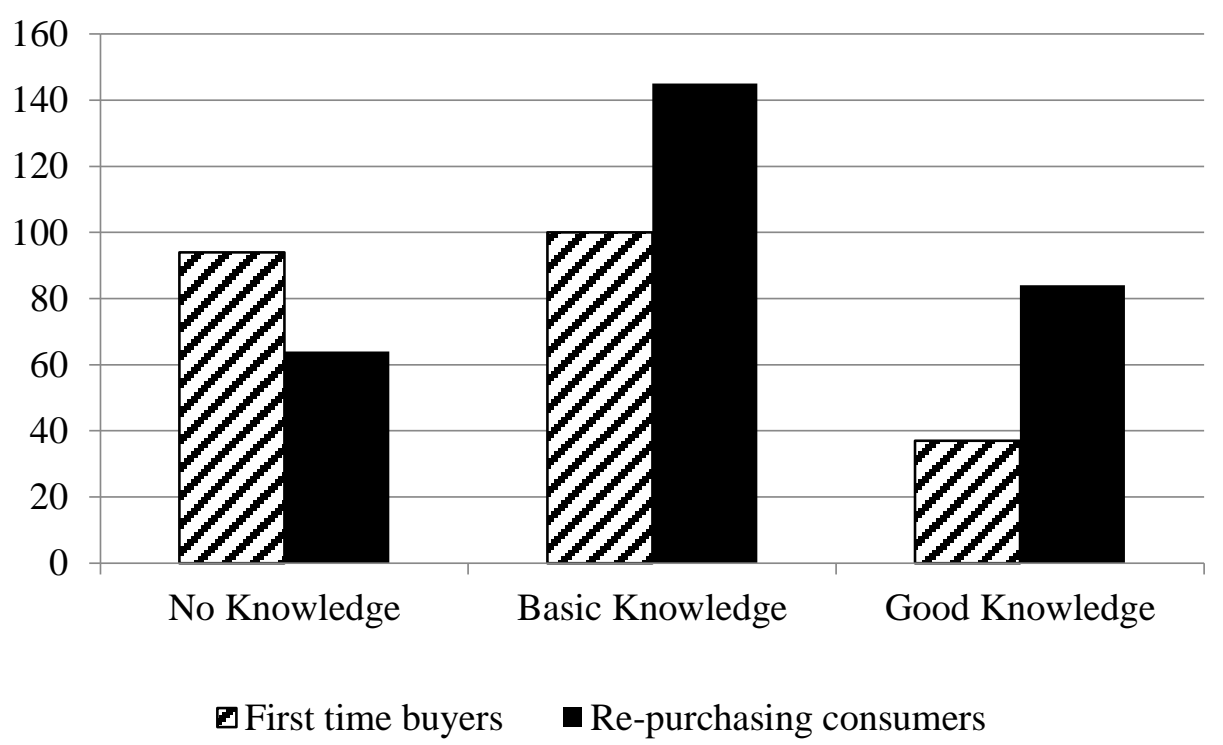

Note: The sample comprises 231 first time buyers and 293 repurchasing consumers. 
Table 1: Sample description

\begin{tabular}{lc}
\hline Demographic variables & Sample Value \\
\hline Average household size & 3.3 \\
Average number of employed persons per household & 2.1 \\
Percentage of households with a child or children & $40.5 \%$ \\
aged under 18 & 37.7 \\
Average age of the head of the household & $77.7 \%$ \\
Percentage of households with male heads & $55.9 \%$ \\
Percentage of households owning cars & 524 \\
\hline Sample size & \\
\hline
\end{tabular}


Table 2: Correlation and descriptive statistics $(\mathbf{N}=\mathbf{5 2 4})$

\begin{tabular}{|c|c|c|c|c|c|c|c|c|c|c|}
\hline Variables & 1 & 2 & 3 & 4 & 5 & 6 & 7 & 8 & 9 & 10 \\
\hline 1. Subjective knowledge & 1.00 & & & & & & & & & \\
\hline 2. Car ownership & $0.22^{* * *}$ & 1.00 & & & & & & & & \\
\hline $\begin{array}{l}\text { Plan to buy in current or next } \\
\text { 3. year }\end{array}$ & 0.06 & $-0.18^{* * *}$ & 1.00 & & & & & & & \\
\hline 4. Plan to buy in $2-3$ years & 0.04 & -0.00 & $-0.34^{* * *}$ & 1.00 & & & & & & \\
\hline 5. Plan to buy in $4-5$ years & 0.00 & $0.10^{* *}$ & $-0.28^{* * *}$ & $-0.25^{* * *}$ & 1.00 & & & & & \\
\hline 6. No specific purchase plan & -0.10 & $0.10^{* *}$ & $-0.43^{* * *}$ & $-0.38^{* * *}$ & $-0.31^{* * *}$ & 1.00 & & & & \\
\hline 7. Annual household income $\neq$ & $0.12^{* * *}$ & $0.25^{* * *}$ & $0.10^{* *}$ & 0.01 & -0.01 & $-0.09^{* *}$ & 1.00 & & & \\
\hline 8. Gender of household head & 0.04 & 0.03 & 0.03 & -0.01 & 0.01 & -0.03 & $0.08^{*}$ & 1.00 & & \\
\hline 9. Age of household head & $-0.13^{* * *}$ & $0.17^{* * *}$ & -0.07 & -0.05 & 0.02 & $0.09^{* *}$ & $0.08^{*}$ & $0.19^{* *}$ & 1.00 & \\
\hline 10. Proportion of drivers in family & $0.22^{* * *}$ & $0.49^{* * *}$ & -0.03 & -0.03 & -0.02 & 0.07 & $0.21^{* *}$ & -0.01 & 0.01 & 1.00 \\
\hline Mean & 0.93 & 0.56 & 0.28 & 0.23 & 0.17 & 0.32 & 12.54 & 0.78 & 37.74 & 0.47 \\
\hline Standard Deviation & 0.73 & 0.50 & 0.45 & 0.42 & 0.37 & 0.47 & 11.07 & 0.41 & 9.85 & 0.31 \\
\hline Minimum & 0.00 & 0.00 & 0.00 & 0.00 & 0.00 & 0.00 & 1.80 & 0.00 & 21.00 & 0.00 \\
\hline Maximum & 2.00 & 1.00 & 1.00 & 1.00 & 1.00 & 1.00 & 55.00 & 1.00 & 67.00 & 1.00 \\
\hline
\end{tabular}

$* * * p<0.01, * * p<0.05, * p<0.1$. $\neq$ Annual household income is measured in 10,000 RMB.

Note: All significance tests are two-tailed. 
Table 3: Estimation results of ordered probit models

\begin{tabular}{|c|c|c|c|c|c|c|}
\hline \multirow[b]{2}{*}{ Variables } & \multicolumn{2}{|c|}{ Model 1: Whole sample } & \multicolumn{2}{|c|}{ Model 2: RPCs only } & \multicolumn{2}{|c|}{ Model 3: FTBs only } \\
\hline & Coefficient & $\mathrm{t}$-value & Coefficient & $\mathrm{t}$-value & Coefficient & $\mathrm{t}$-value \\
\hline$\overline{\text { Constant }}$ & 0.35 & 1.32 & 1.28 & $3.50 * * *$ & 0.28 & 0.70 \\
\hline Household income & 0.04 & $2.54 * *$ & 0.00 & 0.81 & 0.05 & $1.81 *$ \\
\hline Age of the head of the household & -0.03 & $-4.66 * * *$ & -0.01 & $-1.90 *$ & -0.03 & $-3.25 * * *$ \\
\hline Gender of the head of the household & 0.72 & $5.5 * * *$ & -0.27 & -1.59 & 0.85 & $4.20 * * *$ \\
\hline Proportion of drivers & 0.63 & $3.59 * * *$ & 0.35 & 1.31 & 0.71 & $2.69 * * *$ \\
\hline Car ownership & 0.55 & $3.03 * * *$ & & & & \\
\hline \multicolumn{7}{|l|}{ Purchasing goal } \\
\hline \multicolumn{7}{|c|}{ - Plan to buy in current or next year (Reference category) } \\
\hline - Plan to buy in $2-3$ years & 0.05 & 0.36 & 0.02 & 0.11 & 0.11 & 0.53 \\
\hline - Plan to buy in 4-5 years & -0.22 & -1.38 & -0.02 & -0.09 & -0.22 & -0.91 \\
\hline - No specific purchase plan & -0.56 & $-4.09 * * *$ & -0.07 & -0.38 & -0.65 & $-3.14 * * *$ \\
\hline Ordered threshold value $\left(\alpha_{2}\right)^{\#}$ & 1.48 & $17.99 * * *$ & 1.38 & $14.52 * * *$ & 1.52 & $11.82 * * *$ \\
\hline Log-likelihood at convergence & \multicolumn{2}{|c|}{-465.88} & \multicolumn{2}{|c|}{-298.07} & \multicolumn{2}{|c|}{-198.54} \\
\hline$\underline{\text { Pseudo R-square }}$ & \multicolumn{2}{|c|}{0.16} & \multicolumn{2}{|c|}{0.02} & \multicolumn{2}{|c|}{0.16} \\
\hline
\end{tabular}

$* * * p<0.01, * * p<0.05, * p<0.1$

Note: "the first ordered threshold $\alpha_{1}$ is normalized to zero. All significance tests are two-tailed. 
Table 4: Effect of FTBs' SK on price preference

\begin{tabular}{lrrrrrr}
\hline & \multicolumn{3}{c}{ Price alternatives (RMB) } & \multicolumn{2}{c}{ Test of independence against } \\
repurchasing consumers $\left(\chi^{2}\right)$ & d.f. & $p$ \\
\hline RPCs & $<100 \mathrm{k}$ & $100-200 \mathrm{k}$ & $>200 \mathrm{k}$ & & & \\
FTBs & 55 & 149 & 89 & 67.46 & 2 & $<0.01$ \\
FTB * No SK & 103 & 114 & 14 & 50.76 & 2 & $<0.01$ \\
FTB * Basic SK & 50 & 39 & 5 & 38.36 & 2 & $<0.01$ \\
FTB * Good SK & 11 & 54 & 4 & 5.47 & 2 \\
\hline
\end{tabular}

Table 5: Effect of FTBs' SK on Country of Origin preference

\begin{tabular}{lcccccccc}
\hline & \multicolumn{4}{c}{ Country of Origin (COO) alternatives } & \multicolumn{2}{c}{ Test of independence against } \\
& Chinese & European & Other Asian & American & Not Specified & repurchasing consumers $\left(\chi^{2}\right)$ & d.f. & $p$ \\
\hline RPCs & 23 & 148 & 60 & 22 & 40 & 37 & 32.42 & 4 \\
FTBs & 45 & 89 & 25 & 35 & 19 & 28.47 & 40.01 \\
FTB * No SK & 22 & 33 & 8 & 12 & 19 & 21.14 & 4 \\
FTB * Basic SK & 19 & 36 & 13 & 17 & 15 & $5.73^{\#}$ & 4 \\
FTB * Good SK & 4 & 20 & 4 & 6 & 3 & 0.01 \\
\hline
\end{tabular}

Note: ${ }^{\#}$ Although some expected numbers in this $\chi^{2}$ test are less than 5 , it still fails to reject $\mathrm{H}_{0}$ on the homogeneous COO preferences between two groups. 
Table 6: Effect of FTBs' SK on fuel efficiency preference

\begin{tabular}{|c|c|c|c|c|c|c|}
\hline & \multicolumn{3}{|c|}{ Fuel efficiency alternatives (liter/100km) } & \multirow{2}{*}{$\begin{array}{l}\text { Test of independence against } \\
\text { repurchasing consumers }\left(\chi^{2}\right)\end{array}$} & \multirow[b]{2}{*}{ d.f. } & \multirow[b]{2}{*}{$p$} \\
\hline & $<8$ & $8-10$ & $>10$ & & & \\
\hline RPCs & 46 & 87 & 65 & & & \\
\hline FTBs & 42 & 83 & 23 & 13.38 & 2 & $<0.01$ \\
\hline FTBs * No SK & 20 & 23 & 6 & 10.41 & 2 & 0.01 \\
\hline FTBs * Basic SK & 15 & 40 & 11 & 7.35 & 2 & 0.03 \\
\hline FTBs * Good SK & 7 & 20 & 6 & 3.72 & 2 & 0.16 \\
\hline
\end{tabular}

Table 7: Effect of FTBs' SK on top speed preference

\begin{tabular}{|c|c|c|c|c|c|c|c|c|}
\hline & \multicolumn{5}{|c|}{ Top speed alternatives (km/hour) } & \multirow{2}{*}{$\begin{array}{l}\text { Test of independence against } \\
\text { repurchasing consumers }\left(\chi^{2}\right)\end{array}$} & \multirow[b]{2}{*}{ d.f. } & \multirow[b]{2}{*}{$p$} \\
\hline & $<150$ & $150-180$ & $180-210$ & $>210$ & Not specified & & & \\
\hline RPCs & 27 & 56 & 57 & 40 & 28 & & & \\
\hline FTBs & 22 & 76 & 28 & 8 & 25 & 28.91 & 4 & $<0.01$ \\
\hline FTBs $*$ No SK & 10 & 29 & 6 & 0 & 7 & 26.05 & 4 & $<0.01$ \\
\hline FTBs $*$ Basic SK & 7 & 31 & 14 & 5 & 15 & 13.20 & 4 & 0.01 \\
\hline FTBs $*$ Good SK & 5 & 16 & 8 & 3 & 3 & $6.33^{\#}$ & 4 & 0.18 \\
\hline
\end{tabular}

Note: ${ }^{\#}$ Although some expected numbers are less than 5 , it still fails to reject $\mathrm{H}_{0}$ on the homogeneous top speed preferences between two groups. 